\title{
AN OBSERVATIONAL STUDY OF CESAREAN TRENDS AT A TEACHING HOSPITAL IN PUNJAB
}

\author{
SUPARNA GROVER ${ }^{1}$, SUNITA MEENA ${ }^{1}$, AJAY CHHABRA ${ }^{2 *}$
}

${ }^{1}$ Department of Obstetrics and Gynaecology, Government Medical College, Amritsar. ${ }^{2}$ Department of Medicine, Government Medical College, Amritsar. E-mail: drajaychhabra@gmail.com

Received: 30 October 2021, Revised and Accepted: 09 November 2021

ABSTRACT

Objectives: The objective of the study was to study the indications and risk factors for caesarean section (CS) and to study the caesarean rates in various patient groups as per Robson's classification.

Methods: This prospective observational study was conducted at Government Medical College Amritsar over a period of six months. All the patients admitted for delivery beyond 22 weeks were allotted to Robson groups on admission and the indications of all CS were recorded. The data collected were tabulated and analyzed statistically.

Results: There were 553 deliveries in the study period, of which there were 241 CS amounting to a caesarean rate of $43.6 \%$. Nulliparity, previous caesarean delivery and malpresentation were significant risk factors for CS but induction of labor was not associated with increased probability of caesarean delivery. Previous caesarean delivery was the most common indication of CS followed by foetal distress. Among Robson groups, group 10 had the biggest group size and biggest contribution to cesarean rates followed by group 5 .

Conclusion: Tertiary care government hospitals have a higher cesarean rates due to referral of high-risk pregnancies. Increasing the rates of trial of labour after caesarean is one of the interventions that may serve to decrease the caesarean rates in such institutions.

Keywords: Caesarean section, Robson's classification, Trial of labor after caesarean, Vaginal birth after caesarean.

(C) 2021 The Authors. Published by Innovare Academic Sciences Pvt Ltd. This is an open access article under the CC BY license (http://creativecommons.org/ licenses/by/4.0/) DOI: http://dx.doi.org/10.22159/ajpcr.2021v14i12.43264. Journal homepage: https://innovareacademics.in/journals/index.php/ajpcr

\section{INTRODUCTION}

The increasing caesarean rates across the globe have been a matter of serious concern as well as controversy. Caesarean Section (CS), when medically indicated, has played a major role in saving many maternal and neonatal lives that would have been lost in pre-cesarean era and caesarean rates are one of the measures to assess the maternal care services. The WHO statement on caesarean rates in 2015, however, emphasized that when the caesarean rates at population level cross $10 \%$ of all deliveries, there is no significant benefit in terms of reduction in maternal and perinatal mortality rates [1].

Caesarean rate in India according to NFHS-4 (2015-16) was $17.2 \%$ which was almost two times the cesarean rates as per NFHS-3(2005-6) [2]. The same survey showed the CS rate in the state of Punjab to be $24.6 \%$ with rates in private sect as high as $39.7 \%$ against $17.8 \%$ in public sector.

The WHO recommends the use of Robson classification of all patients admitted for delivery in order to assess and compare, the cesarean rates and trends [3]. This classification assigns the pregnant women admitted for delivery to one of the ten distinct groups based on parity, onset of labor, number of foetuses, lie and presentation of the foetus and gestational age [4]. While groups one to nine are distinct, welldefined groups, all representing different risk factors for a CS, group ten is a rather heterogeneous group in which all pregnancies with less than 37 weeks gestation and single foetus in cephalic position are included irrespective of the parity and history of previous caesarean section.

\section{Aims and objectives}

The present study was done at a Government teaching hospital in Punjab with the following objectives:

1. To study the indications and risk factors for cesarean section.

2. To study the caesarean rates in various patient groups as per Robson Ten Group Classification.

\section{METHODS}

The study was conducted in one of the obstetric units of Government Medical College Amritsar from January 2021 to June 2021. It was an observational study that did not involve any intervention at the level of patient care.

All the patients admitted for delivery beyond 22 weeks were allotted to Robson groups on admission itself as per the criteria mentioned in WHO guidelines (Table 1) [3]. Exclusion criteria included those who delivered at less than 22 weeks gestation or with fetal birth weight $<500$ gand those who underwent laparotomy for rupture uterus. Allocation to group 10 (preterm birth at $<37$ weeks gestation with single foetus in cephalic presentation) was done on the basis of gestational age on the day of delivery.

The data collected was studied statistically with online MedCalc ( calculator. All the calculations were done with $95 \%$ CI and $\mathrm{p}<0.05$ was considered statistically significant.

We also studied the most common indications for induction of labour and CS from the indoor records of all patients.

In Robson classification, the prevalence of each group was calculated in the study population along with group caesarean rate and relative contribution was calculated in percentage by the following formula.

Relative contribution $(\%)=$ no. of CS in group/Total no. of CS in the hospital $\times 100$

\section{RESULTS}

There were 553 deliveries in the period, of which there were 241 CS amounting to a caesarean rate of $43.6 \%$. Overall, $63(11.39 \%)$ women had planned CS before onset of labor pains and rest were all emergency surgeries. 71 (29.46\%) CS were done at $<37$ weeks gestation. 
Table 1: Robson classification reporting table

\begin{tabular}{|c|c|c|c|c|c|c|c|c|}
\hline Gp & & $\begin{array}{l}\text { Total no. of } \\
\text { women }\end{array}$ & $\begin{array}{l}\text { Group } \\
\text { size }(\%)\end{array}$ & $\begin{array}{l}\text { No. of vaginal } \\
\text { delivery }\end{array}$ & No. of CS & $\begin{array}{l}\text { CS rate in each } \\
\text { group (\%) }\end{array}$ & $\begin{array}{l}\text { Relative CS } \\
\text { rate }(\%)\end{array}$ & $\begin{array}{l}\text { Absolute } \\
\text { CS rate } \\
(\%)\end{array}$ \\
\hline 1 & $\begin{array}{l}\text { Nulliparous women at } \geq 37 \text { weeks } \\
\text { gestation with single foetus } \\
\text { with cephalic presentation in } \\
\text { spontaneous labour }\end{array}$ & 119 & 21.52 & 88 & 31 & 26.05 & 12.86 & 5.6 \\
\hline $2 \mathrm{~A}$ & $\begin{array}{l}\text { Nulliparous women at } \geq 37 \text { weeks } \\
\text { gestation with single foetus } \\
\text { with cephalic presentation with } \\
\text { induced labour }\end{array}$ & 34 & 6.15 & 21 & 13 & 38.23 & 5.39 & 2.35 \\
\hline $2 \mathrm{~B}$ & $\begin{array}{l}\text { Nulliparous women at } \geq 37 \text { weeks } \\
\text { gestation with single foetus } \\
\text { with cephalic presentation with } \\
\text { prelabour CS }\end{array}$ & 7 & 1.26 & & 7 & 100 & 2.9 & 1.26 \\
\hline 3 & $\begin{array}{l}\text { Parous women without previous } \\
\text { CS at } \geq 37 \text { weeks gestation } \\
\text { with single foetus with cephalic } \\
\text { presentation in spontaneous } \\
\text { labour }\end{array}$ & 67 & 12.11 & 56 & 11 & 16.42 & 4.56 & 1.99 \\
\hline $4 \mathrm{~A}$ & $\begin{array}{l}\text { Parous women without previous } \\
\text { CS at } \geq 37 \text { weeks gestation } \\
\text { with single foetus with cephalic } \\
\text { presentation with induced labour }\end{array}$ & 19 & 3.43 & 18 & 1 & 5.26 & 0.41 & 0.18 \\
\hline 4B & $\begin{array}{l}\text { Parous women without previous } \\
\text { CS at } \geq 37 \text { weeks gestation } \\
\text { with single foetus with cephalic } \\
\text { presentation with prelabour CS }\end{array}$ & 1 & 0.18 & & 1 & 100 & 0.41 & 0.18 \\
\hline 5.1 & $\begin{array}{l}\text { Parous women with previous } 1 \text { CS } \\
\text { at } \geq 37 \text { weeks gestation with single } \\
\text { foetus with cephalic presentation } \\
\text { with induced labour }\end{array}$ & 47 & 8.5 & 1 & 46 & 97.87 & 19.09 & 8.32 \\
\hline 5.2 & $\begin{array}{l}\text { Parous women with previous more } \\
\text { than } 1 \text { CS at } \geq 37 \text { weeks gestation } \\
\text { with single foetus with cephalic } \\
\text { presentation with induced labour }\end{array}$ & 23 & 4.16 & & 23 & 100 & 9.54 & 4.16 \\
\hline 6 & $\begin{array}{l}\text { Nulliparous women with Single } \\
\text { fetus with breech presentation }\end{array}$ & 20 & 3.62 & 10 & 10 & 50 & 4.15 & 1.81 \\
\hline 7 & $\begin{array}{l}\text { Parous women with Single fetus } \\
\text { with breech presentation }\end{array}$ & 27 & 4.88 & 8 & 19 & 70.37 & 7.88 & 3.43 \\
\hline 8 & Pregnancy with multiple foetuses & 11 & 1.99 & 6 & 5 & 45.45 & 2.07 & 0.9 \\
\hline 9 & Pregnancy with transverse lie & 3 & 0.54 & 0 & 3 & 100 & 1.24 & 0.36 \\
\hline \multirow[t]{2}{*}{10} & $\begin{array}{l}\text { Women with single fetus with } \\
\text { cephalic presentation at } \leq 37 \text { weeks }\end{array}$ & 175 & 31.64 & 104 & 71 & 40.57 & 29.46 & 12.43 \\
\hline & & 553 & 100 & 312 & 241 & 43.58 & 100 & 43.58 \\
\hline
\end{tabular}

Demographic profiles of women delivering during the study period and pregnancy outcomes have been portrayed in Fig. 1.

$264(47.74 \%)$ of the pregnant women were nulliparous while $289(52.26 \%)$ were parous. Of these, $126(22.78 \%)$ had history of CS in past. The overall caesarean rate amongst nulliparous women was $31.8 \%$ while it was $22.08 \%$ in parous women without previous CS. Caesarean rate was $96 \%$ amongst the women with history of CS. Amongst all pregnant women with single foetus in cephalic presentation, nulliparity (OR 1.97, p=0.0097) and history of previous CS (OR 61.91, p<0.0001) were significant risk factor for CS

215 of deliveries were preterm while 338 were term deliveries. The caesarean rate amongst preterm deliveries was $43.26 \%$ as against $43.79 \%$ amongst term deliveries. Amongst all pregnant women with singleton cephalic foetus with no previous CS, preterm birth was not associated with increased chances of CS (OR 0.86, $\mathrm{p}=0.54$ ).

Amongst 341 women without previous CS, with a single foetus in cephalic presentation, labour induction was done in 80 women and another 261 presented with spontaneous onset labour. Cesarean rate was $20 \%$ amongst those who underwent induction of labour against $25.29 \%$ amongst those who had a spontaneous onset labour. Cesarean rate was higher amongst 53 women who had a term induction, i.e., $26 \%$ as against $7 \%$ among 27 women who had induction at preterm gestation. The most common indication for labour induction was premature rupture of membranes (PROM) in 37 cases followed by hypertensive disorders of pregnancy in 24 cases. Induction of labor was not associated with statistically significant increased chances of CS, irrespective of the parity or gestational age (OR $0.74, \mathrm{p}=0.17$ ).

Two factors that were found to be positively associated with chances of CS in women without any previous caesarean were multiple pregnancy (OR 3.21, p=0.08) and breech presentation (OR 3.51, p=0.0002), of which the latter had a statistically significant association.

The indications of 241 cesarean deliveries performed are listed in Table 2. The most common indication was previous CS (46.47\%) followed by foetal distress/hypoxia (21.58\%), together accounting for about two thirds of all cesarean deliveries. Placenta previa was 


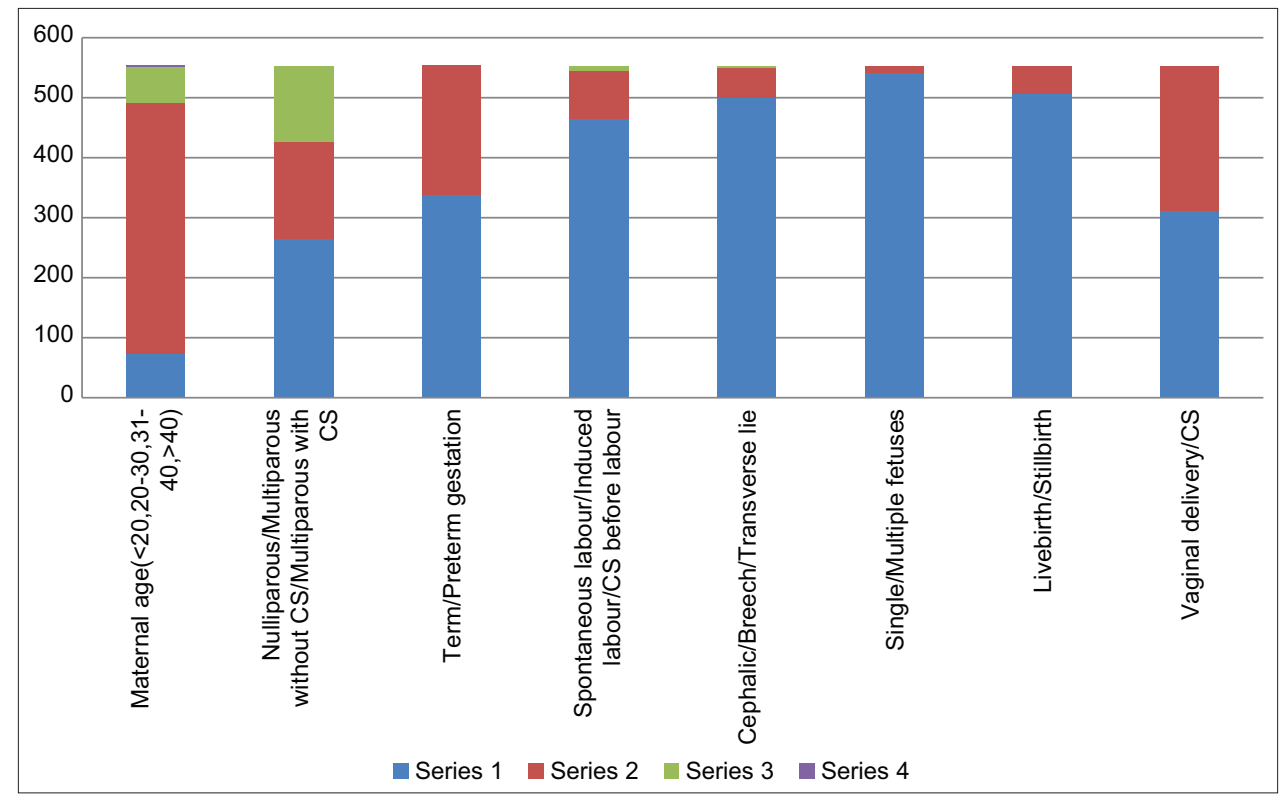

Fig. 1: Profile of parturients and pregnancy outcomes

Table 2: Distribution of all caesarean deliveries based on primary indication of caesarean

\begin{tabular}{lll}
\hline Indication of CS & N=No. of women & Percentage of total CS \\
\hline $\begin{array}{l}\text { Previous CS } \\
\text { Fetal distress (on CTG) }\end{array}$ & 112 & 46.5 \\
or Fetal hypoxia (on & & 21.6 \\
radiological & \\
investigations) & \\
Abnormal lie/ & 35 & \\
malpresentation & & 14.5 \\
Abnormal labour (first & 16 & \\
stage/second stage & & 6.6 \\
abnormalities/ & & \\
obstructed labour) & & \\
Placenta previa & 9 & 3.7 \\
Abruption placenta & 3 & 1.2 \\
CPD & 6 & 2.5 \\
Failed induction & 3 & 1.2 \\
Maternal distress & 3 & 1.2 \\
Others & 2 & 0.8 \\
Total & 241 & \\
\hline
\end{tabular}

an indication in 9 women without previous CS and it was a comorbid condition in nine women with previous CS. Six of these nine women with previous CS had placenta accreta syndrome and underwent a caesarean hysterectomy.

According to Robson classification (Table 1), the biggest group was group $10(31.64 \%)$, followed by group $1(21.52 \%)$, group $5(12.66 \%)$ and group $3(12.11 \%)$ respectively.

The maximum contribution to overall caesarean rate was from group 10 (29.46\%) and group 5(28.63\%).

Group 1and 2 (that included nulliparous women at $\geq 37$ weeks gestation with single foetus with cephalic presentation) constituted $28.9 \%$ of total deliveries while group 3 and 4 (that included multiparous women without a previous uterine scar at $\geq 37$ weeks gestation with single foetus with cephalic presentation) constituted $15.73 \%$ of all deliveries. The combined caesarean rate among Group $1-4$, was $64 / 247=25.91 \%$. It was $22.58 \%(42 / 186)$ in those who had spontaneous onset of labour pains. $7 / 20(35 \%)$ caesarean deliveries in group 2 were done before onset of labor pains for indications such as fetal hypoxia, placenta previa, and CPD.

The most common indications of CS in these four groups were foetal distress (FHR abnormalities or foetal hypoxia, 36/64, 56.25\%) and labor abnormalities $(14 / 64,21.87 \%)$

Group 5 (Parous women with single cephalic pregnancy $\geq 37$ weeks gestation with at least one previous uterine scar) contributed $12.66 \%$ but when considering all cases with previous CS, including group 7,8 , and 10 , the total number of these women was $126(22.78 \%)$. While group 5 contributed to $28.63 \%$ of all CS, the overall contribution of previous CS as the indication for caesarean was $46.47 \%$.

Amongst all 126 patients with previous CS, 34(26.98\%) patients had previous 2 or more CS, 35 (27.77\%) had comorbid conditions such as anaemia/hypertension/diabetes nine patients had placenta previa (7.14\%), 8 (6.35\%) had breech presentation, 6 (4.76\%) had PROM with unfavourable Bishop score, 6 (4.76\%) had previous caesarean within past 2 years, $5(3.97 \%)$ had placenta-foetal insufficiency, $3(2.38 \%)$ had borderline or inadequate pelvis and $2(1.9 \%)$ had multiple gestation. The option for trial of labor after CS (TOLAC) was given to $18(14.28 \%)$ women, was refused by $12(9.5 \%)$ and vaginal birth after caesarean (VBAC) was successful in $5(3.97 \%)$ of the 6 women who chose TOLAC.

Overall abnormal lie and mal-presentations accounted for $9.58 \%$ of all deliveries and cesarean rate amongst these patients was $66 \%$. Caesarean rates in group 6 (nulliparous single breech) and 7 (multiparous single breech) in our study were $50 \%$ and $70 \%$, respectively. Among the ten assisted vaginal breech deliveries in group 6, 50\% were already diagnosed with intrauterine fetal demise, $20 \%$ had fetal anomaly and remaining $30 \%$ were in advanced labor on admission.

Group 9 that included all pregnancies with transverse lie, had the smallest size but 100 percent cesarean rate.

There were 11 cases of multiple gestation and cesarean rate was $45.45 \%$. Among these 11 cases, three caesarean were done due to malpresentation of the first twin and two were done due to history of previous CS. Six women had a vaginal delivery in this group.

Group 10 was the largest group in numbers (31.64\%) as well as in terms of its contribution to overall caesarean rate $(29.46 \%)$. The most 
Table 3: Comparison of group specific CS rates amongst various studies

\begin{tabular}{|c|c|c|c|c|c|c|c|c|c|c|c|c|}
\hline \multirow[t]{2}{*}{ Study } & \multirow{2}{*}{$\begin{array}{l}\text { Biggest } \\
\text { group by size }\end{array}$} & \multirow{2}{*}{$\begin{array}{l}\text { Groups making biggest } \\
\text { contribution to caesarean } \\
\text { rate }\end{array}$} & \multicolumn{10}{|c|}{ Group specific CS rates } \\
\hline & & & 1 & 2 & 3 & 4 & 5 & 6 & 7 & 8 & 9 & 10 \\
\hline Present study & 10 & 10,5 & 26 & 49 & 16.5 & 10 & 98.5 & 50 & 70.5 & 45.5 & 100 & 40.5 \\
\hline Konar [5] & 1 & 1,5 & 42 & 60.5 & 24.5 & 34 & 95.5 & 65.5 & 56.5 & 60 & 100 & 27.5 \\
\hline Jamwal [6] & 1 & 5,2 & 32 & 61.5 & 4 & 8.5 & 99 & 100 & 91.5 & 75 & 100 & 48 \\
\hline Shenoy [7] & 2 & 5,2 & 48 & 52.5 & 1 & 20.5 & 100 & 93.5 & 100 & 89 & 100 & 91 \\
\hline Kant [8] & 2 & 2,5 & 18.5 & 69.5 & 6 & 22.5 & 94.5 & 100 & 100 & 100 & 100 & 51 \\
\hline Dar [11] & 1 & 5,2 & 16 & 49 & 6 & 26 & 97 & 86 & 73 & 29 & 100 & 39 \\
\hline Dhodapkar [12] & 1 & 5,1 & 23.5 & 33.5 & 6 & 12 & 90 & 100 & 100 & 76.5 & 100 & 33 \\
\hline
\end{tabular}

common indication of cesarean in this group was a history of previous CS $(41 / 71,57.75 \%)$ followed by foetal distress $(16 / 71,22.53 \%) .27$ women in this group underwent induction of labor and the cesarean rate amongst them was $7.4 \% \%$. The most common indication of induction was preterm PROM (19) followed by hypertensive disorders [5,6].

\section{DISCUSSION}

Globally past few decades have seen rapid increase in caesarean rates. While the facilities for CS remain one of the critical intervention in emergency obstetric care, equally critical is the fact that CS should always be done only for medical indications and not otherwise [1].

The cesarean rate in the present study of $43.6 \%$ is similar to the results of Konar $(43.13 \%)$ and Jamwal $(46.12 \%)$ but lesser than the results of Shenoy (57.88\%) and Kant (53.86\%) [5-8]. At the same time, our cesarean rates are much higher than Mittal (23.7\%), Prameela (29.33\%), Dar (36.11\%), and Dhodapkar (32.6\%) [9-12]

Amongst the indication of CS, our results of most common indication previous CS (46.47\%) followed by foetal distress/hypoxia (21.58\%) were quite similar to that of Dar (previous LSCS $44.74 \%$, foetal distress $16.82 \%$ ) but the proportion of caesarean due to failed induction was only $1.24 \%$ in our study against $9.37 \%$ in the study by Dar [11].

Group 5 (Term gestation with cephalic presentation with a history of previous CS) was the third biggest group in our study in terms of group size $(12.66 \%)$ and second biggest $(28.63 \%)$ in its contribution to caesarean rate, similar to the results by $\operatorname{Mittal}(29.4 \%)$ [9].

In fact, total women with previous CS in our study were $22.78 \%$ and it was $11.14 \%$ in study by Mittal but the major difference was that a successful VBAC was done in only $3.97 \%$ of these women in our study while it was done in $17.6 \%$ in the latter study [9]. Previous CS was an indication in $46.47 \%$ of total caesarean in our study. Group 5 had a group size of $9-20 \%$ in other studies which had a group cesarean rate between $90-100 \%$ and it contributed to $27-40 \%$ of total cesareans in them [6-13]. The Group-specific CS Rates amongst various Indian studies have been compared in Table 3 .

This analysis once again emphasizes the dominos effect that increasing caesarean rates have towards further increasing cesarean incidence as was described by Vogel [14]. This will be more evident if women with previous CS that are included in group 10 due to preterm birth, are also included in group 5.

The only way to counter this dominos effect is by decreasing primary caesarean rates and encouraging TOLACs. Robson guidelines recommend caesarean rates in this group to be $50-60 \%$ [2]. The major barriers experienced by us in offering TOLAC were more than 1 previous caesarean deliveries (27\%), comorbid conditions (28\%) like anaemia, hypertension, diabetes, refusal for TOLAC by the pregnant woman $(10 \%)$, placenta previa (7\%) and small inter-pregnancy intervals $(6 \%)$ which were similar to findings by Dhodapkar [12]. Mittal reported previous multiple uterine scars (15.6\%), fetal distress (30\%), signs of impending rupture (28\%), failed induction (13\%) and CPD (19\%)as main impediments to VBAC in addition to woman's refusal for TOLAC (10\%) [9]. Dar reported fetal distress (26\%), scar tenderness (19\%) and CPD (12\%) as main indications for repeat cesarean [11].

Group 1 and 2 contributed $28.93 \%$ of all deliveries and $21.45 \%$ of total cesarean deliveries in our study. Other studies reported the contribution of group $1+2$ to total deliveries from $44-50 \%$ and the contribution to cesarean rates was between 33\% and 46\% [5-12] (Table 3). Prameela, on the other hand, reported $48 \%$ of women in these groups with only $11.8 \%$ contribution to caesarean rate [10]. According to Robson guidelines, these two groups usually represent $35-42 \%$ of obstetric population and caesarean rates of $10 \%$ in group 1 are achievable and in group 2 should be around $20-35 \%$ [2].

Our results of caesarean rates in group 1 of $26 \%$ and in group 2 of about $48 \%$ are definitely higher than these guidelines but can be explained by the fact that most of our patients were high-risk pregnancies referred due to complications such as hypertension, and IUGR. and fetal distress was the most common indication of CS in these two groups (58.8\%). Our caesarean rate of group 1 was similar to Dhodapkar (23.5\%) [12], higher than 6-18\% in studies by Prameela [10], Dar [11] and Kant [8] but lesser than 32-48\% in other studies.[5-7] Our CS rates of group 2 were similar to Shenoy(52.5\%) [7], Dar [11] (48.8\%) and Prameela [11] (49\%) but lesser than $60-70 \%$ rates found by other studies [5-8] (Table 3).

We did not find induction of labor to be associated with increased probability of CS (OR $0.74, p=0.16$ ) regardless of gestational age and parity.

Group 3 and 4 formed $15.71 \%$ of the study and its contribution to caesarean rate was just $4.56 \%$ for group 3 and even lesser $0.36 \%$ for group 4 which are much lesser than the cut off of $3 \%$ and $15 \%$ given in Robson guidelines for group 3 and 4 respectively [2]. The smaller size of group $3+4$ can be a reflection of relatively bigger size of group 5 in a tertiary care center. Other studies reported the group size of $3+4$ to be more than $20 \%$ of all deliveries but contribution to caesarean rates were $<10 \%$ [9-12]. Konar on the other hand reported $26.3 \%$ of all deliveries and $15.6 \%$ of all caesarean deliveries to be from group $3+4$ [5] (Table 3).

Group 10 was the largest group in our study both in terms of group size as well as the relative contribution to caesarean rates (29.6\%). This group represents all the singleton deliveries with cephalic presentation at a gestation less than 37 weeks. In our study more than two-third of women in group 10 (68.57\%) were between 34 and 37 weeks gestation. The caesarean rates of this group in our study was $40.57 \%$ which was higher than the $30 \%$ rates as per Robson guidelines [2]. Studies showed a wide variation regarding caesarean rate $(23-91 \%)$ in group 10 whereas Prameela [10] reported caesarean rates as low as $11.13 \%$ (Table 3). This wide variation is also the result of a heterogeneous composition of group 10.

We didn't find preterm birth to be a risk factor for CS and the higher caesarean rate and the highest relative contribution to caesarean 
rate was mainly because of the women with previous caesarean who contributed to $57.7 \%$ of caesareans in this group. Amongst the women in group 10 with no previous CS, the most common indication of CS was fetal distress. The rate of induction of labour in this group was $20.77 \%$ that was similar to induction rate of $21.46 \%$ amongst women with single foetus in cephalic presentation at term gestation but cesarean rate was just $7.4 \%$ amongst the preterm induction group against $26.4 \%$ when induction was done at term gestation.

The small size of group 6, 7 and $9(3.6 \%, 4.9 \%, 0.5 \%)$ and their relatively low $(5.6 \%)$ contribution to caesarean deliveries was similar to results of most of the studies [5-13]. Our caesarean rates of $50 \%$ in group 6 (nulliparous single breech) and of 70\% in group 7(multiparous single breech) were very low compared to other studies. Most of other studies showed a CS rates of $95-100 \%$ in these 2 groups [6-9] except Konar [5], Jogia [13] and Dar [11] who reported 65-85\% cesarean rates in group 6 and Prameela [10], Konar [5] and Dar [11] who reported $52-73 \%$ caesarean rates in group 7 (Table 3). Vogel mentions that CS rates of less than $100 \%$ in these groups is an unmet need of CS [14]. In our study, most of the assisted vaginal breech deliveries in group 6 were conducted in women already diagnosed with intrauterine fetal demise, fetal anomaly and those reporting in advanced labour on admission.

Group 9 was a very small group with $100 \%$ caesarean rates and the results were similar in all studies [5-13].

Group 8 representing multiple gestation was another small group with $45 \%$ caesarean rate which was similar to Prameela (52\%) but lesser than the caesarean rates of $60-100 \%$ found in other studies [5-8,10,13]. According to Robson guidelines, caesarean rates in this group can be around 60\% [2].

\section{CONCLUSION}

Previous caesarean is the major risk factor contributing to increasing caesarean rates. Other significant risk factors are nulliparity and malpresentations. Induction of labour, when medically indicated and preterm birth are not associated with increased risk of CS.

Tertiary care government teaching hospitals have a high caesarean rates due to high in-referral of high risk pregnancies. Increasing the rates of TOLAC is one of the interventions that may serve to decrease the caesarean rates in such institutions. Group 1 and 2 is another area of focus in efforts to decrease primary CS.

\section{Strength and weakness of study}

The strength of our study is that we studied not only the trends in CS as per Robson classification but also the indications of CS in different groups. We tested various risk factors for their statistical association with CS. The weakness of our study was a relatively short study period and the fact that we didn't compare the important aspect of effect of mode of delivery on neonatal outcomes in various groups.

\section{AUTHOR'S CONTRIBUTION}

The main concept and study design was prepared by Suparna Grover. Data collection was done by Sunita Meena, while data analysis and preparation of the manuscript was done by Ajay Chhabra.

\section{CONFLICTS OF INTEREST}

Nil.

\section{AUTHOR'S FUNDING}

Authors hereby declare that no financial support or grant was taken from anyone for research, preparation, authorship or publication of this article.

\section{REFERENCES}

1. World Health Organization. WHO Statement on Caesarean Section Rates. Geneva: World Health Organization; 2015. Available from: https://www.who.int/reproductivehealth/publications/maternal_ perinatal_health/cs-statement/en [Last accessed on 2020 Dec].

2. National Family Health Survey of India. National Family Health Survey 2015-16. Available from: http://rchiips.org/nfhs/NFHS-4Report.shtml [Last accessed on $2021 \mathrm{Jan}]$.

3. World Health Organization. Robson Classification: Implementation Manual. Geneva: World Health Organization; 2017. Available from: https://www.who.int/reproductivehealth/publications/maternal perinatal_health/robson-classification/en [Last accessed on $2021 \mathrm{Jan}$ ].

4. Robson MS. Classification of caesarean sections. Fetal Matern Med Rev 2001:12:23-39.

5. Konar H, Sarkar M, Chowdhury SK. Analysis of caesarean section rates using the robson ten-group classification at a tertiary care teaching hospital in Eastern India: A cross-sectional study. J Clin Diagn Res 2021;15:QC24-8.

6. Jamwal D, Sharma P, Mehta A, Pannu JS. Analysis of caesarean sections using Robson's classification system in a tertiary care centre in Northern India: An emerging concept to audit the increasing caesarean section rate. Int J Reprod Contracept Obstet Gynecol 2021;10:2281-5.

7. Shenoy H, Shenoy ST, Anaswara T, Remash K. Analysis of caesarean delivery using Robson ten group classification system at a tertiary care teaching institute in Kerala, India. Int J Reprod Contracept Obstet Gynecol 2019;8:1990-8.

8. Kant A, Mendiratta S. Classification of cesarean section through Robson criteria: An emerging concept to audit the increasing cesarean section rate. Int J Reprod Contracept Obstet Gynecol 2018;7:4674-7.

9. Mittal P, Pandey D, Suri J, Bharti R. Trend prediction for cesarean deliveries based on Robson classification system at a tertiary referral unit of North India. J Obstet Gynecol India 2019;11:1-8.

10. Prameela RC, Shilpa G, Farha A, Prajwal S. Analysis of cesarean section rate using Robson's ten group classification system and comparing the trend at a tertiary hospital for 2 years. J South Asian Feder Obstet Gynaecol 2016;8:175-80.

11. Dar MA, Lone SA, Rashid R. Analysis of caesarean section rates by Robson's classification. J Evid Based Med Healthc 2021;8:1460-5.

12. Dhodapkar SB, Bhairavi S, Daniel M, Chauhan NS, Chauhan RC. Analysis of caesarean sections according to Robson's ten group classification system at a tertiary care teaching hospital in South India. Int J Reprod Contracept Obstet Gynecol 2015;4:745-9.

13. Jogia PD, Lodhiya KK. Analysis of caesarean sections according to modified Robson's ten group classification system at a tertiary care centre in Western India. Int $\mathbf{J}$ Reprod Contracept Obstet Gynecol 2019;8:433-9.

14. Vogel JP, Betrán AP, Vindevoghel N, Souza JP, Torloni MR, Zhang J, et al. Use of the Robson classification to assess caesarean section trends in 21 countries: A secondary analysis of two WHO multicountry surveys. Lancet Global Health 2015;3:e260-70. 